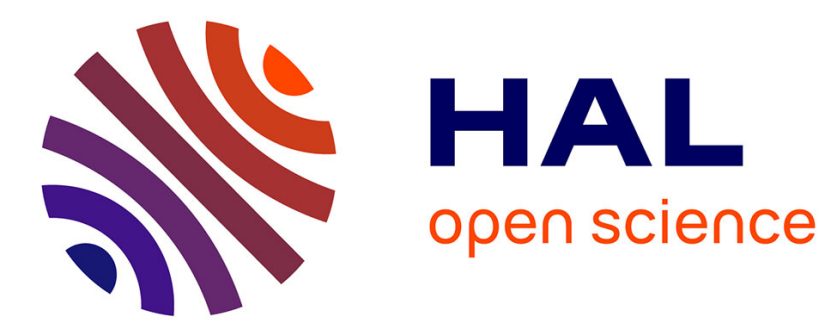

\title{
Prediction of abrasive punch wear in copper alloy thin sheet blanking
}

Edouard Falconnet, Jérôme Chambert, Hamid Makich, Guy Monteil

\section{To cite this version:}

Edouard Falconnet, Jérôme Chambert, Hamid Makich, Guy Monteil. Prediction of abrasive punch wear in copper alloy thin sheet blanking. Wear, 2015, 338-339, pp.144 - 154 . hal-02131360

\section{HAL Id: hal-02131360 \\ https://hal.science/hal-02131360}

Submitted on 16 May 2019

HAL is a multi-disciplinary open access archive for the deposit and dissemination of scientific research documents, whether they are published or not. The documents may come from teaching and research institutions in France or abroad, or from public or private research centers.
L'archive ouverte pluridisciplinaire HAL, est destinée au dépôt et à la diffusion de documents scientifiques de niveau recherche, publiés ou non, émanant des établissements d'enseignement et de recherche français ou étrangers, des laboratoires publics ou privés. 


\title{
Prediction of abrasive punch wear in copper alloy thin sheet blanking
}

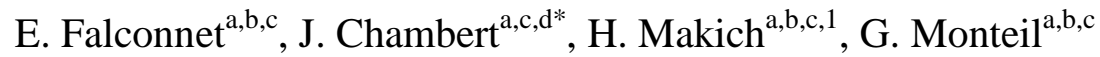 \\ ${ }^{a}$ FEMTO-ST Institute, CNRS UMR 6174, Department of Applied Mechanics, 24 rue de l'Epitaphe, 25000 \\ Besançon, France \\ ${ }^{\mathrm{b}}$ ENSMM, 26 rue de l'Epitaphe, 25030 Besançon Cedex, France \\ ${ }^{\mathrm{c}}$ University Bourgogne Franche-Comté (UBFC) \\ ${ }^{\mathrm{d}}$ University of Franche-Comté, 1 rue Claude Goudimel, 25030 Besançon Cedex, France
}

${ }^{*}$ Corresponding author. Tel.: +33 3816660 25; fax: +33 381666700 .

E-mail address: jerome.chambert@univ-fcomte.fr (J. Chambert).

\section{Highlights}

Wear coefficient and punch wear profiles are defined from experiments. The punch wear profile is fitted by an exponential function.

An original method is proposed to calibrate the shear failure model.

Abrasive wear is more important on the punch flank.

\begin{abstract}
This work presents a combination of finite element simulations of copper alloy thin sheet blanking and a wear algorithm based on Archard formulation for abrasive wear of the punch. Firstly, a tribometer has been specifically designed to measure wear coefficient, and punch worn profiles have been extracted by means of a double-print method. Secondly, the blanking process has been simulated through the finite element method by using an elasto-plastic constitutive model and the shear failure model. Thirdly, a wear algorithm has been programmed using experimental wear data and mechanical fields computed from blanking simulation. Then, a damage criterion, namely the shear failure model, has been calibrated by
\end{abstract}

\footnotetext{
${ }^{1}$ Present address : Ecole des Mines d'Albi, GIP InSIC, 27 rue d'Hellieule, 88100 Saint-Dié-des-Vosges, France
} 
an original method based on stress triaxiality analysis and shear height value measured from blanked edge profile. Finally, punch wear predictions have been discussed and compared to experimental results.

Keywords : Wear testing; Blanking; Copper alloy; Wear modelling; Finite element modelling

\section{Introduction}

Blanking process has been employed for decades in metal industry to obtain quality shaped parts for various applications. The reliability and capability of mass production of this forming process have been used to produce metal supports for electronic components, called leadframes. The manufacturing industries of leadframes have followed the trend in downscaling of electronic components, and thus they have produced smaller parts with high controlled geometry. Gréban et al. [1] have analyzed the influence of blanked materials microstructure on leadframes quality with copper alloy thin sheets, a material chosen for its electrical properties. The authors have found that the mechanical characteristics and microstructure of copper alloys have a strong influence on parts blanking profile. Burr formation on sheared parts remains a critical parameter to control in order to insure leadframes electrical efficiency. For the last decades, the wear of shearing tool has been the locus of several experimental studies to understand its influence on sheared edge quality. Maeda and Matsuno [2] have highlighted the relationship between tool wear and burr height, among other process parameters, in conventional blanking. Cheung et al. [3] have studied the effects of several process parameters on dam-bar (integrated circuit component) cutting tools wear, and have established relationships between punch flank wear, burr height and cutting force. Monteil et al. [4] have developed a direct method to measure wear on cylindrical 
punch, based on selective activation technique, which allows real time quantification of process parameters influence like blanked material nature or lubrication.

Hence, the versatility of numerical methods has been combined to experimental investigations to predict tool wear for a variety of forming processes. Jensen et al. [5] have applied finite element method (FEM) to determine tool wear in conventional deep-drawing. Behrens and Schaefer [6] have performed hot forging process simulation by means of finite element modeling to predict tool wear. More recently, Torres et al. [7] have used FEM to simulate hot metal shearing process and have found good correlation between stress distributions within the tool and wear location observed on tool real shape. However, tool wear prediction has been less investigated in blanking process. Hambli [8] has proposed a theoretical approach to predict tool wear according to the evolution of punch edge radius, which has been implemented in industrial software called Blanksoft to optimize sheet metal blanking processes. Moreover, Hambli [9] has implemented a wear prediction model within finite element (FE) code to predict punch wear during steel metal sheet blanking, and has also investigated the effect of tool wear on burr formation. More recently, Falconnet et al. [10] have combined experimental and numerical analyses to study punch wear in the blanking of copper alloy thin sheet used to produce leadframes. In this study, the material behavior has been modeled with an elasto-plastic law without considering material damage. Several authors have emphasized the fact that accurate representation of metal shearing processes implies to take account of crack initiation and propagation mechanism within finite element simulation.

In this paper, investigations on punch wear prediction presented in Falconnet et al. [10] have been extended by introducing a finite element blanking model including crack initiation and propagation within blanked sheet by means of shear failure model. Data of the studied blanking configuration and wear measurements have been determined from experimental 
results. Then, the finite element modeling of blanking process has been established and punch wear calculation has been performed. Results concerning damage parameter calibration and punch worn profile are presented and discussed in the last section of this paper.

\section{Experimental setup}

\subsection{Material data}

The blanked material is a copper-iron alloy with chemical composition listed in Table 1.

\begin{tabular}{lllll}
\hline Element & $\mathrm{Cu}$ & $\mathrm{Fe}$ & $\mathrm{P}$ & Others \\
wt.\% & $>99.61$ & $0.05-0.15$ & $0.025-0.04$ & $<0.2$ \\
\hline
\end{tabular}

Table 1. Chemical composition of the blanked material.

Samples have been taken from a copper-iron alloy strip of $15 \mathrm{~mm}$ width and $0.254 \mathrm{~mm}$ nominal thickness to perform conventional tensile tests, at strain rate of $10^{-3} \mathrm{~s}^{-1}$.

The rational (true-stress and true-strain) tensile test curve has been described by the following piecewise power hardening law:

$\sigma=\left\{\begin{array}{lll}\sigma_{0}+k_{0}\left(\bar{\varepsilon}^{p}\right)^{n_{0}} & \text { where } & \sigma_{0} \leq \sigma<\sigma_{1} \\ \sigma_{1}\left(\bar{\varepsilon}^{p} / \varepsilon_{1}\right)^{n_{1}} & \text { where } & \sigma>\sigma_{1}\end{array}\right.$

where $\sigma$ is the flow stress, $\bar{\varepsilon}^{p}$ is the equivalent plastic strain, $k_{0}$ is a material constant, $\sigma_{0}$ is the initial yield stress, $\left(\sigma_{1}, \varepsilon_{1}\right)$ is the yield point at incipient necking, and $n_{0}$ and $n_{1}$ are strain hardening exponents. As long as a homogeneous uniaxial stress state exists, i.e. until incipient necking occurs, the tensile test curve (Fig.1) has been interpolated by the first part of Eq. (1). 


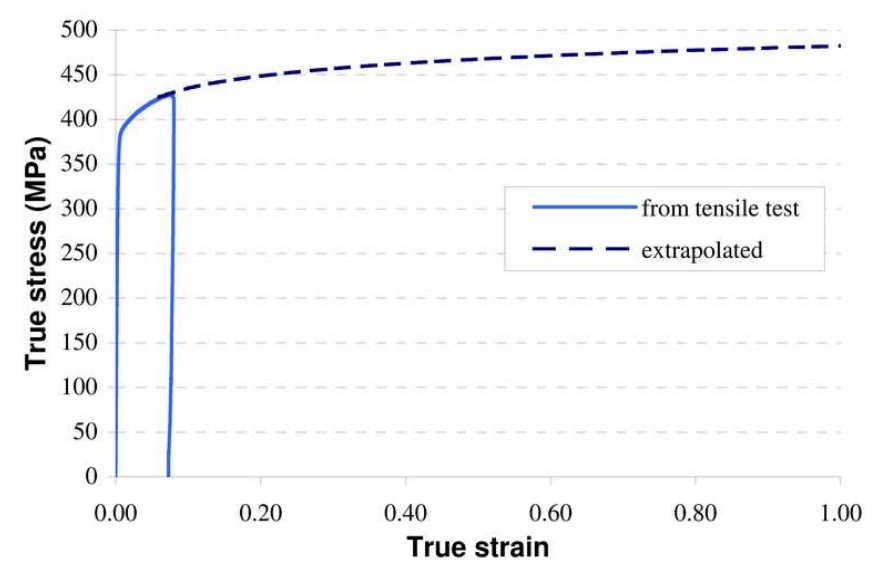

Fig. 1. Uniaxial true-stress - true-strain curve of the blanked material.

Beyond this point, an extrapolation of the tensile test curve has been performed according to the second part of Eq. (1) to take into account large deformation plasticity within FE modelling. The Poisson's ratio $v$ has been provided by metal sheet supplier. The mechanical properties are listed in Table 2.

\begin{tabular}{lll}
\hline Parameter & Symbol & Value \\
Young's modulus & $E$ & $121 \mathrm{GPa}$ \\
Poisson's ratio & $v$ & 0.34 \\
Initial yield strength & $\sigma_{0}$ & $371 \mathrm{MPa}$ \\
Yield strength at incipient & $\sigma_{1}$ & $422 \mathrm{MPa}$ \\
necking & & \\
Equivalent plastic strain at & $\varepsilon_{1}$ & 0.055 \\
incipient necking & & $215 \mathrm{MPa}$ \\
Material constant & $k_{0}$ & 0.490 \\
Strain hardening exponent & $n_{0}$ & \\
of interpolated curve & & 0.045 \\
Strain hardening exponent & $n_{1}$ & \\
of extrapolated curve & &
\end{tabular}

Table 2. Mechanical properties of the blanked material. 


\subsection{Blanking test description}

The studied blanking process consists in a cylindrical punch passing through a metal sheet maintained between a die and a sheet-holder (Fig. 2).

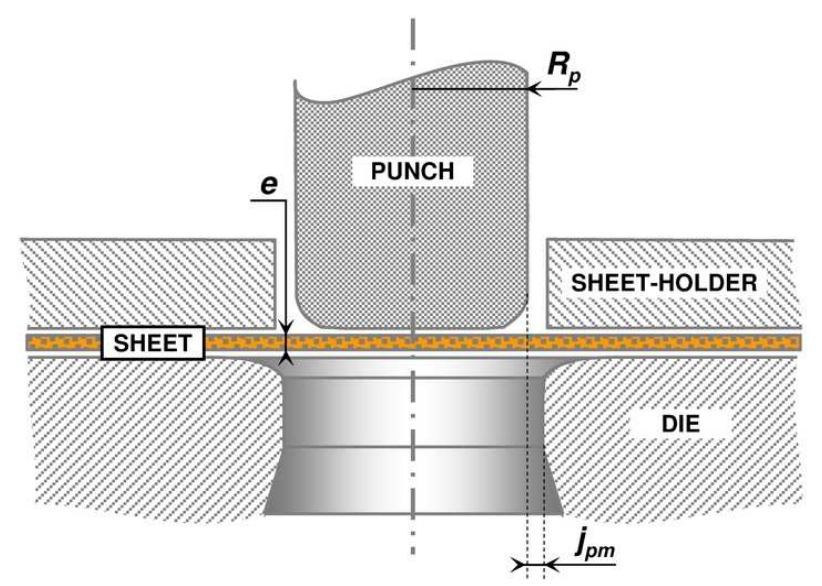

Fig. 2. Blanking test configuration.

During downstroke travel, the punch plastically deforms the sheet to create local shear stresses which lead to ductile damage and then complete separation of the cut part. The sheetholder prevents elastic springback and movement of the sheet during punch travel, thus increasing the quality of the blanked edge. In this study, the punch radius $R_{p}$ measures $1.85 \mathrm{~mm}$ and the clearance $j_{p m}$ between the punch and die equals $10 \mu \mathrm{m}$, or $4 \%$ relative to sheet thickness. The blanked material is a copper-iron alloy sheet of $254 \mu \mathrm{m}$ nominal thickness $e$, and $15 \mathrm{~mm}$ width. The punch has been made of H20S tungsten carbide, a tool material commonly used in leadframes manufacturing, and it has been obtained by spark machining. The blanking tests have been performed on a mechanical press with a speed of 500 strokes/min.

Fig. 3 represents typical cut edge profile generated during the blanking process. 


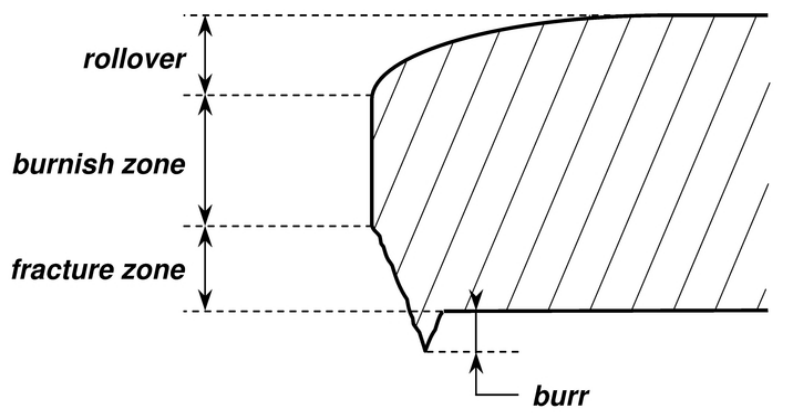

Fig. 3. Blanking edge profile scheme.

According to Johnson and Slater [11], rollover results from bending of the sheet which occurs during the initial plastic indentation stage by the punch. As the tool further penetrates the sheet, cracks initiate at the cutting edge of the tool and propagate inside the sheet. Complete fracture occurs before the punch totally passes through the sheet. The burr and fracture zone are formed during this stage. Finally, burnish zone results from friction contact between punch flank and sheet which leads to a polished surface.

\subsection{Wear data}

In order to consider wear phenomenon within FE simulation, wear data from experiments have been required. As mentioned in Falconnet et al. [10], abrasive wear has been quantified not only by determining a wear coefficient for the studied material couple, but also by measuring punch profile.

\subsubsection{Determination of wear coefficient}

A specific tribometer designed by Makich [12] has been used to determine a wear coefficient between tungsten carbide and copper-iron alloy. This tribometer has been originally developed as a tool for decision support in industrial context to qualify relative abrasivity among different blanked sheet materials. As illustrated in Fig. 4, this tribometer consists in a 
$5 \mathrm{~mm}$ diameter spherical pin in contact with the non-lubricated copper alloy sheet by applying a 7 N normal load.

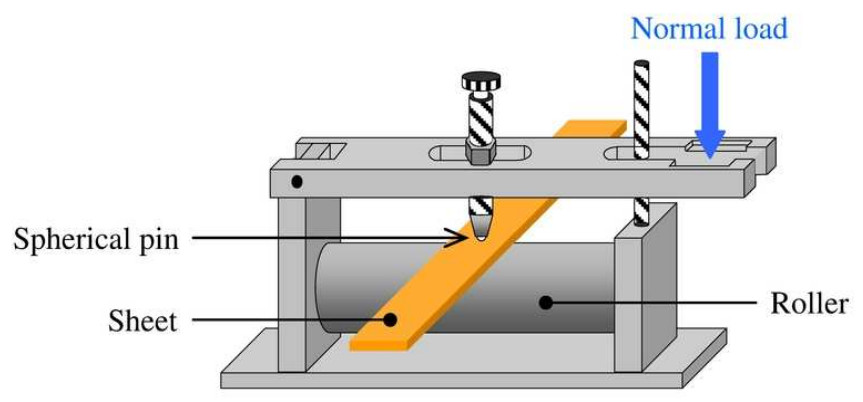

Fig. 4. Specific tribometer design.

Since the tribometer has been developed specifically to be integrated on a production line, the metal sheet is unrolled from a coil with a continuous speed of $37 \mathrm{~mm} / \mathrm{s}$ imposed by the stroke rate of the mechanical press (500 strokes/min). This configuration has been chosen to permit the rubbing surface to be constantly renewed, contrary to conventional tribometers (i.e. pinon-disc or ring-on-ring) where the wear track remains the same during the tribological experiment. Thus, the contact setup (friction conditions) get closer to the one met during the blanking process, since the punch penetrates undamaged sheet at each stroke.

In Makich's work [12], several blanking materials have been tested in comparison with a reference material, which is the material studied in this paper. During a previous study on copper alloy thin sheet blanking performed by Gréban [13], friction tests have been carried out between this material and tungsten carbide on a pin-on-disc laboratory tribometer. Different values for parameters such as applied load, pin diameter, and lubrication have been trialled and the results of this study have served to set Makich's tribometer parameters values. The wear coefficient $K$ has been evaluated by means of the Archard wear formulation [14] which relates the wear volume $V$ to the applied $\operatorname{load} F_{N}$, the sliding distance $s$ and the wear coefficient. This coefficient has been originally defined as a material constant traducing the 
probability that an asperity contact produces a wear particle. After a determined sliding distance, the spherical pin has been removed from the tribometer to measure its volume using 3D topographic acquisition method. The detailed procedure has been described in Falconnet et al. [10]. The wear data from this tribological test are listed in Table 3.

\begin{tabular}{lll}
\hline Parameter & Symbol & Value \\
Worn volume & $V$ & $3.31 \times 10^{-4} \mathrm{~mm}^{3}$ \\
Sliding distance & $S$ & $2250 \mathrm{~m}$ \\
Applied load & $F_{N}$ & $7 \mathrm{~N}$ \\
Wear coefficient & $K$ & $2.1 \times 10^{-11} \mathrm{~mm}^{2} / \mathrm{N}$ \\
& & \\
\hline
\end{tabular}

With this method, a value of $2.1 \times 10^{-11} \mathrm{~mm}^{2} / \mathrm{N}$ has been obtained for the wear coefficient $K$ of the studied material couple.

\subsubsection{Punch wear profile}

Observations of the real punch by Scanning Electron Microscope have shown regrinding streaks perpendicular to the blanking direction on the brand-new punch (Fig.5a), and have revealed typical wear streaks parallel to the blanking direction, involving a purely abrasive wear mechanism on the worn punch (Fig.5b). 

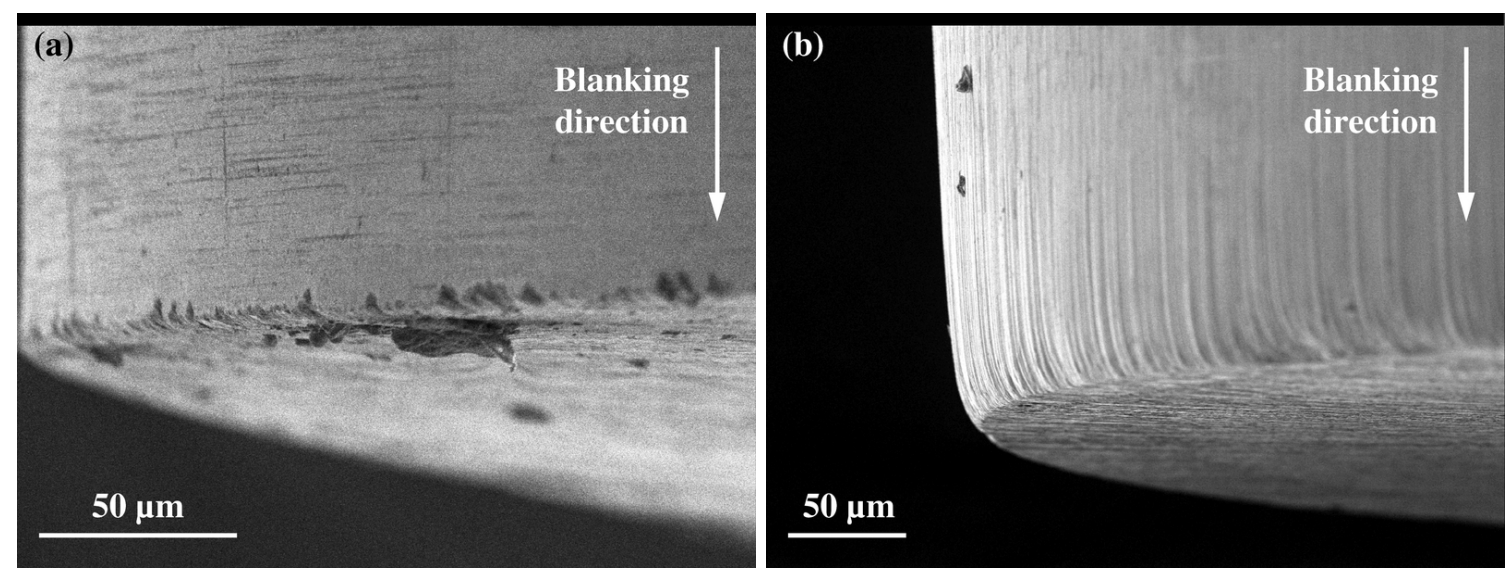

Fig. 5. Scanning electron micrograph: (a) real brand-new punch (500 magnification) and (b) real worn punch (300 magnification).

In order to measure punch wear profile without removing the tool from the mechanical press, and thus affecting the blanking test setting, a double-print method has been developed. The first step has consisted in obtaining the punch imprint by immersion of the punch tip in a mould filled with silicone resin. After a drying period, a second silicon resin compatible with the first one has been used to produce punch replica. Then, the replica has been processed with variable focus optical microscope (InfiniteFocus ${ }^{\circledR}$ ) to extract 3D surfaces from which an averaged profile has been generated. Finally, punch profile has been positioned according to reference planes determined outside worn areas. Fig. 6 illustrates three punch profiles obtained by this method. 


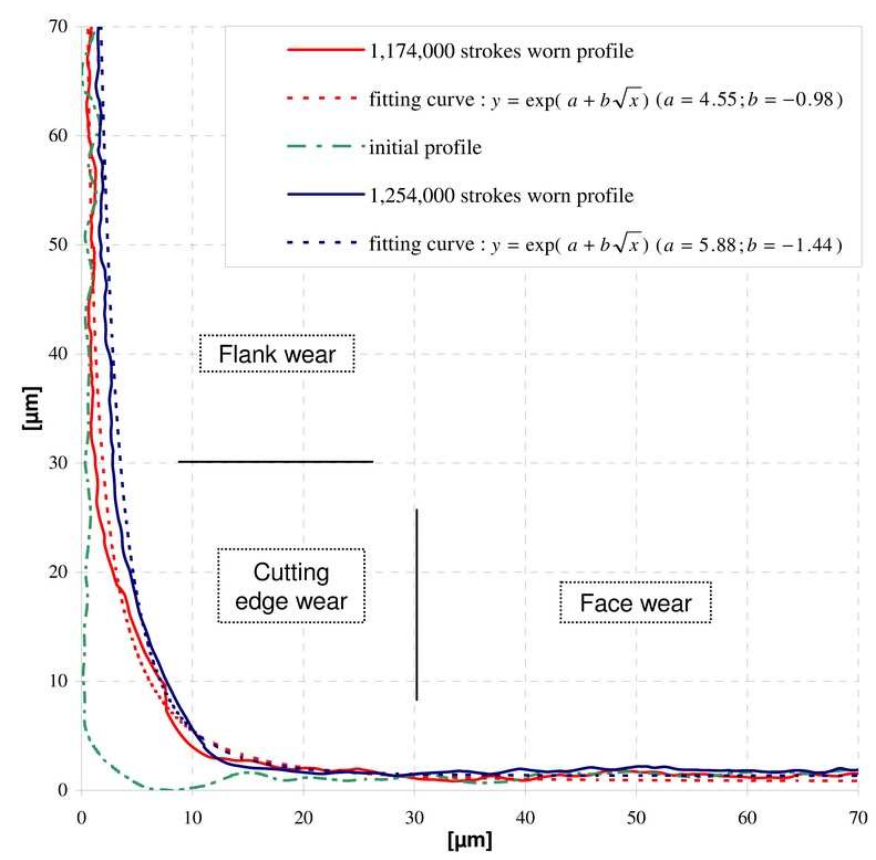

Fig. 6. Initial profile, worn profiles $(1,174,000$ and $1,254,000$ punch strokes) and corresponding fitting curves from a punch replica.

The initial profile has been obtained after regrinding of the punch, and the worn profiles have been measured after 1,174,000 and 1,254,000 punch strokes. Hernandez et al. [15] have proposed to decompose the punch worn profile in three zones: face wear, cutting edge wear and flank wear (Fig. 6).

Several authors have suggested simplified geometrical approximations of tool wear in sheet metal blanking. Hambli [8] has observed that tool wear status can be related to punch edge radius value. Hernandez et al. [15] have approached punch tool wear by means of two characteristic dimensions, namely the radial wear length and axial wear length. Shivpuri et al. [16] have assumed that tool wear always starts from the same location and follows an angle along punch edge. In the present study, punch worn profiles have been approximated by exponential fitting curves according to Makich [12] work. The exponential curves fitting worn profiles after 1,174,000 and 1,254,000 punch strokes have been represented in Fig. 6 with their respective mathematical equations. The resulting punch profile representation has been implemented in a numerical simulation for accurate punch geometry modelling. 


\section{Numerical modelling of the blanking process}

\subsection{Damage and fracture modelling}

In the last decades, numerous experimental and numerical studies have been undertaken to obtain a better understanding of the shearing and failure mechanisms which happen in the blanking process. Nevertheless, physical micromechanisms such as large deformation, ductile fracture and crack propagation are still difficult to model. Experimental studies conducted by Atkins [17] have shown that ductile fracture by nucleation, growth and coalescence of microvoids is involved within the sheet metal blanking process. According to Lemiale et al. [18], numerical modelling of ductile fracture in the blanking process can be performed by using two main approaches: un-coupled and coupled models.

In the un-coupled approach, a mathematical function depending on the loading history and the strain path is used as a damage indicator without modifying the material behaviour of the sheet. Several damage criteria have been proposed in the literature. For example, Taupin et al. [19] have carried out numerical simulations of blanking process by using the McClintock criterion [20]. Goijaerts et al. [21] have compared an adapted version of the Rice and Tracey criterion [22] with a new criterion also based on the stress triaxiality in order to predict the ductile fracture initiation in blanking process. In the context of blanking process, Farzin et al. [23] have applied the shear failure model available in Abaqus code [24], which is based on the accumulation of equivalent plastic strain as a failure criterion.

In the coupled approach, the ductile damage variable has a strong influence on the plastic yield function which describes the material behaviour of the sheet. Within this approach, two main fields must be distinguished. The first one called the continuum damage mechanics is based on the thermodynamics of irreversible processes. As an example, Hambli and Potiron [25] have applied the ductile damage model proposed by Lemaitre [26] for the simulation of 
sheet metal blanking process. The second one is related to the micromechanics of ductile fracture by void nucleation, growth and coalescence. Among the numerous studies performed, Klingenberg and Singh [27] have used the GTN model [28,29] to simulate the punching process. However, the GTN model is based on the mechanics of spherical voids growth submitted to axisymmetric stress states at high stress triaxialities, and, as a consequence, is theoretically unable to describe the mechanisms of shear fracture under conditions of low stress triaxiality such as those encountered within blanking process. Recently, Nahshon and Hutchinson [30] and Nielsen and Tvergaard [31] have proposed a phenomenological extension of the GTN model to shear-dominated states by modifying the damage growth rate. More recently, this modified GTN model and the shear failure model have been applied by Achouri et al. [32] to simulate the punching process for high-strength low-alloy steels. By comparing their numerical results with experimental ones, they have shown that the modified GTN model provides better predictions of the punch penetration at fracture initiation for low values of the normalized clearance between the punch and the die $(<13 \%$ relative to sheet thickness). Nevertheless, the trend is totally inversed for a high value of normalized clearance (33\%). Even if the modified GTN model appears as a promising way for the simulation of blanking process, it requires a complex identification strategy of the numerous material parameters by coupling simulations and experimental tests on specimens with different shapes and stress states [33].

Furthermore, Ghosh et al. [34] have compared the GTN model and the shear failure model with some experimental micrographs for the shearing process with block type blades. They have demonstrated by comparison with experimental observations that the fracture initiation and crack propagation modelling by means of the shear failure model is better suited than with the GTN model. 
For all these reasons, the shear failure model has been chosen to predict the crack initiation and propagation when the damage indicator $\omega$ reaches the value one [24]. This damage indicator is defined as:

$$
\omega=\sum_{n}\left(\frac{\Delta \bar{\varepsilon}^{p}}{-\bar{\varepsilon} f}\right)
$$

where $\Delta \bar{\varepsilon}^{p}$ is the increment of equivalent plastic strain. The plastic strain at failure $\bar{\varepsilon}_{f}^{p}$ is a damage parameter which can be described as a function of the plastic strain rate, stress triaxiality and temperature. The summation is carried out over $n$ increments. In the following of this article, only stress dependence of the plastic strain at failure has been assumed.

\subsection{Wear modelling}

Wear has been the subject of several studies over the past in attempts to develop predictive governing models. Phenomenological models using principles of contact mechanics as an approach have been proposed by several authors, the most important one being the Archard [14] wear equation. In forming applications, the Archard wear model has proven to be a suitable solution to depict wear phenomenon of surfaces since it consists in a simple linear relation between material volume loss, contact pressure and sliding distance. More precisely, this model is based on a phenomenological approximation of the adhesive wear mechanism which considers the load and sliding distance in the interface of two contacting bodies. The Archard model has been considered in this study to be well suitable in connection with a finite element model, since each variable can be calculated within the blanking simulation. Several studies have been conducted by coupling the Archard wear model with finite element simulation of various metal forming processes. Behrens and Schaefer [6] have used the Archard model with variable hardness to calculate tool wear during hot forging. Lepadatu et al. [35] have analyzed die wear evolution during metal extrusion process by means of Archard 
equation. Ersoy-Nürnberg et al. [36] have developed a modified Archard model related on dissipated energy to estimate die wear in deep drawing application. Hambli [9] has developed a finite element model for sheet metal blanking, and has programmed an algorithm based on Archard equation to predict punch wear.

According to Hambli [9], the Archard wear equation for abrasive wear can be expressed as follows:

$V=K \cdot F_{N} \cdot s$

where $V$ is the worn volume, $K$ is the wear coefficient depending on the material couple and contact conditions, $F_{N}$ is the applied load and $s$ is the sliding distance. In this study, FE blanking simulation has provided each variable necessary for wear calculation, and the Archard wear equation has been implemented under Matlab® environment as follows. For a representative elementary volume of material, Eq. (3) can be written:

$d V=K \cdot d F_{N} \cdot d s$

where $d V$ is the elementary wear volume, $d F_{N}$ the elementary normal load, and $d s$ the elementary variation of sliding distance (Fig.7). 
(a)

(b)

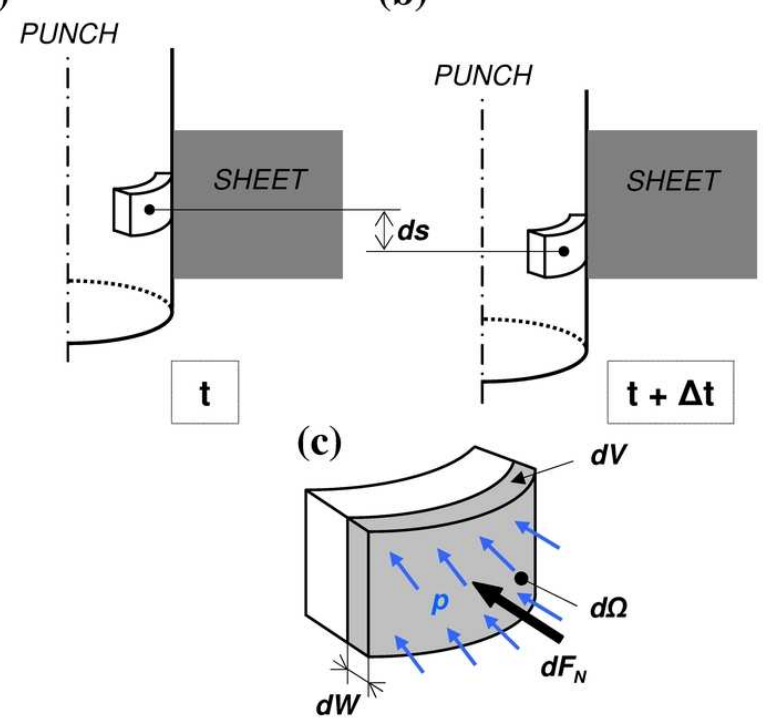

Fig. 7. Schematic representation of the adopted wear model for axisymmetric blanking: (a) global configuration at instant $t$; (b) global configuration at instant $(t+\Delta t)$; (c) detailed view of representative elementary volume at punch surface at instant $(t+\Delta t)$.

The wear depth $d W$ and contact pressure $p$ can be made apparent by introducing the elementary contact area $d \Omega$ by means of the relations $d V=d W \cdot d \Omega$ and $d F_{N}=p \cdot d \Omega$ :

$d W=K \cdot p \cdot d s$

Finite element simulation provides data at each increment over a time interval $[t, t+\Delta t]$. However, the explicit resolution scheme requires many more increments compared to the implicit scheme used in [10]. Thus, requested variables have been written at a predefined frequency for computational efficiency, so the simulation has been divided in several frames. In the following, an increment $n$ corresponds to one frame and increment $(n+1)$ is related to the consecutive frame. The incremental expression for Eq. (5) has been programmed following an Euler integration scheme:

$W_{p_{i}}^{n+1}=W_{p_{i}}^{n}+K \cdot p_{P_{i}}^{n+1} \cdot\left(s_{n}^{n+1}\right)_{P_{i}} \quad$ with $\quad\left(s_{n}^{n+1}\right)_{P_{i}}=\left\|s_{P_{i}}^{n+1}|-| s_{P_{i}}^{n}\right\|$

where $W_{P_{i}}^{n}$ is the wear depth at increment $n$ calculated for a given punch node $P_{i}$ of coordinates $\mathbf{x}_{i}$ and $p_{P_{i}}^{n+1}$ is the contact pressure at increment $(n+1)$ expressed at the same node. 
$s_{P_{i}}^{n}$ corresponds to the cumulated sliding distance at increment $n$ and can be negative depending on the nodes sliding direction. Thus, absolute values have been used to calculate $\left(s_{n}^{n+1}\right)_{P_{i}}$, the sliding distance between increments $n$ and $(n+1)$.

Unlike equations presented in Falconnet et al. [10] where contact pressure has been computed on sheet nodes, Abaqus/Explicit@ contact algorithm has allowed to calculate contact pressure directly at punch nodes. However, sliding distance values provided only at slave nodes by the FSLIP variable in Abaqus/Explicit ${ }^{\circledR}$ have therefore been computed at sheet surface nodes.

Then, sliding distance value on punch $s(\mathbf{x})$ has been obtained by integration of sliding distance value from the sheet $s(\mathbf{y})$ along the punch profile $l$ :

$$
\left\{\begin{array}{l}
s(\mathbf{x})=\frac{1}{\phi(\mathbf{x})} \int_{l} s(\mathbf{y}) \varphi(\mathbf{x}-\mathbf{y}) \mathrm{d} \mathbf{y} \\
\phi(\mathbf{x})=\int_{l} \varphi(\mathbf{x}-\mathbf{y}) \mathrm{d} \mathbf{y}
\end{array}\right.
$$

where $\mathbf{x}$ and $\mathbf{y}$ correspond to the coordinate vectors of the punch nodes and the sheet surface nodes, respectively. The non-local modelling developed by Pijaudier-Cabot and Bazant [37] has again been considered to calculate only the weighted average value of the sliding distance $\left(s_{n}^{n+1}\right)_{T_{j}}$ obtained from the sheet nodes $T_{j}$ (coordinates $\left.\mathbf{y}_{j}\right)$ nearby the considered punch node $P_{i}$ (coordinates $\mathbf{x}_{i}$ ). This weighting operation is schematically represented in Fig.8.

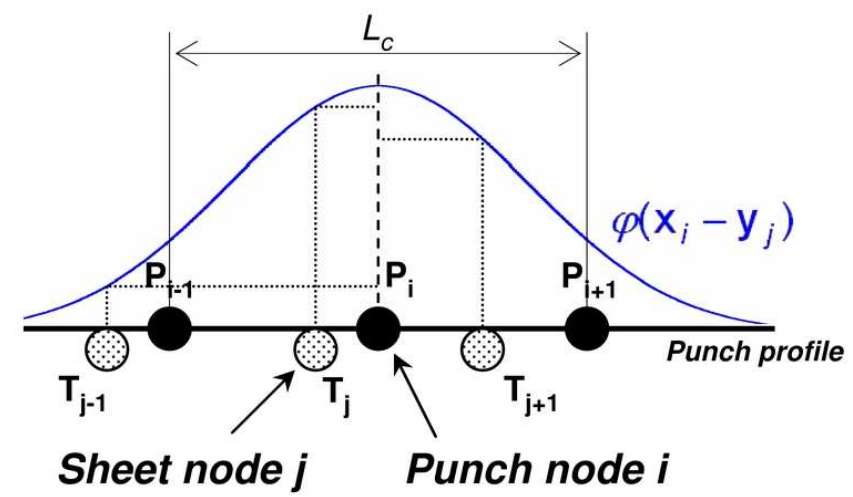

Fig. 8. Schematic representation of the weighting function operation performed around punch node $P_{i}$ to transfer sliding distance values from sheet nodes to punch node $\mathbf{P}_{\mathbf{i}}$. 
Applying a discrete integral form of Eq.(7) to the wear depth at node $P_{i}$ expressed in Eq.(6) leads to the following equation:

$$
\begin{aligned}
& W_{P_{i}}^{n+1}=W_{P_{i}}^{n}+\frac{N_{P} \cdot K \cdot p_{P_{i}}^{n+1}}{\phi\left(\mathbf{x}_{i}\right)}\left[\sum_{j=1}^{N}\left(s_{n}^{n+1}\right)_{T_{j}} \cdot \varphi\left(\mathbf{x}_{i}-\mathbf{y}_{j}\right)\right] \\
& \text { with } \phi\left(\mathbf{x}_{i}\right)=\sum_{j=1}^{N} \varphi\left(\mathbf{x}_{i}-\mathbf{y}_{j}\right) \text { and } \varphi\left(\mathbf{x}_{i}-\mathbf{y}_{j}\right)=\exp \left[-\left|\mathbf{x}_{i}-\mathbf{y}_{j}\right|^{2} / L_{c}^{2}\right]
\end{aligned}
$$

where $L_{C}$ is a parameter which determines the sheet nodes number $N$ considered for the weighting operation. The value $L_{C}=2 t_{P}$, where $t_{P}$ is the punch element size, has been chosen in this study so the sliding distance quantity from one surface sheet node is fully reported during its movement between two punch nodes. The constant $N_{P}$ introduces the punch strokes number. Since wear calculation is performed during the steady-state wear stage, one can approximate wear after several punch strokes by multiplying wear depths obtained from one punch stroke by a punch strokes number. However, care must be taken when choosing this parameter (punch strokes number) in order to avoid large modification of punch profile shape which can significantly influence stress and pressure fields at contact interface.

According to the weighting function definition, maximum weight is attributed when the sheet node passes by the considered punch node and minimum weight as the sheet node moves away, thus providing a realistic approach of the local wear/contact behaviour.

Once wear depth has been computed for each increment of the process simulation, the values have been normally projected on the punch profile nodes.

\subsection{Numerical simulation parameters}

Blanking process modelling has been conducted under Abaqus/CAE 6.11® environment using large-deformation theory [24]. The solution has been computed by means of included explicit solver Abaqus/Explicit@ based on a central-difference time integration rule combined 
with a global stable increment estimator algorithm. The choice of this solver has been motivated by the ability to use the shear failure model for damage modelling (see section 3.1). Axisymmetry modelling has been employed due to the revolution geometry of the problem, thus only one meridian plane of the model has been considered (Fig.9).

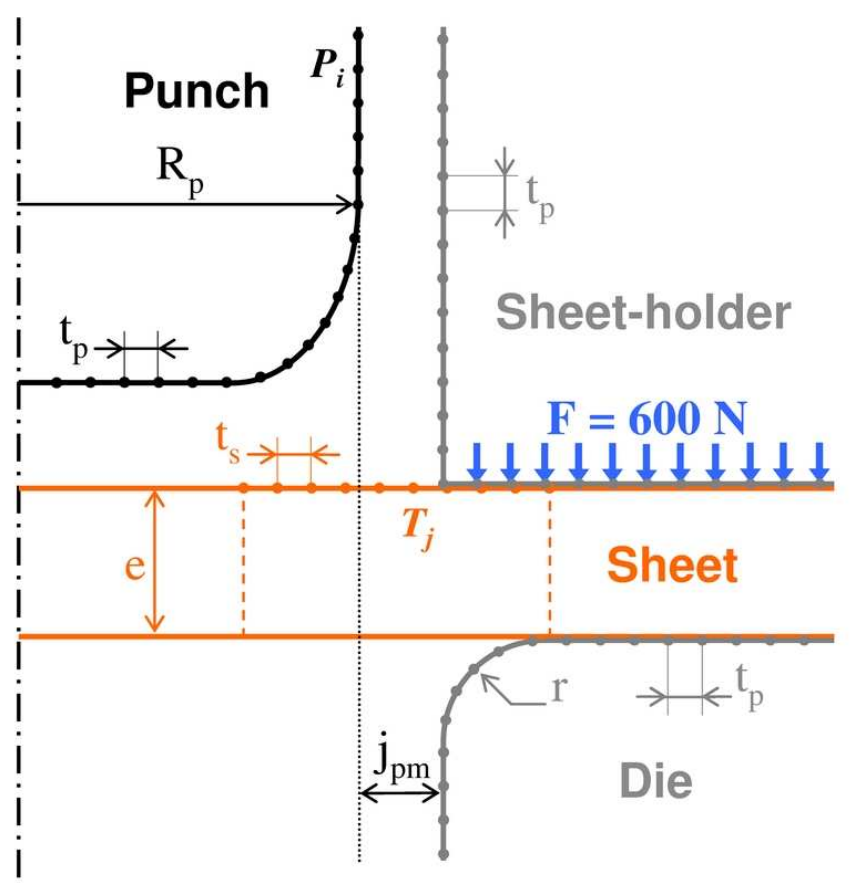

Fig. 9. Axisymmetric blanking simulation setup.

The sheet mechanical properties described in section 2.1 have been included into the numerical model by means of an elasto-plastic von Mises constitutive law with isotropic hardening. Strain rate effect on material behaviour has not been taken into account in this study. As described in section 3.1, the shear failure model provided in Abaqus ${ }^{\circledR}$ has been employed to take account of damage. Element deletion method has been considered to represent crack propagation: when the failure criterion is met within given FE, this element is removed from sheet mesh.

The punch, die and sheet-holder have been meshed with 1D rigid elements. The 1,174,000 punch strokes worn profile has been considered in this study, so the corresponding exponential fitting curve (Fig. 6) has been used to model the punch geometry. The punch 
speed has been set to $0.2 \mathrm{~m} / \mathrm{s}$ according to the stroke rate of the mechanical press. According to Hambli [38], the punch is more constrained than the die, which explains why punch wear is superior to die wear. Moreover, Hambli [38] has suggested that tool edge radius is closely related to the tool wear status. Since die wear has not been considered during the present experimental study, a constant curvature radius has been chosen for the die cutting edge, and the radius value has been estimated according to the minimum curvature of the punch worn profile. For the sheet mesh, quadrangular first order axisymmetric elements with reduced integration have been used to model the shear band located within punch and die clearance. Fine mesh at this location has also been required to collect sliding distance data on the sheet surface for wear calculation. A coarse mesh has been applied elsewhere to reduce simulation computational cost, with a smooth transition mesh built each side of the fine mesh zone by means of triangular first order axisymmetric elements.

The contact formulation has been managed by Abaqus ${ }^{\circledR}$ penalty contact algorithm with the punch profile defined as the master surface and the sheet boundary as the slave surface. Coulomb law with friction coefficient value of 0.1 has been employed to model contact between the sheet, the die and the sheet-holder. No friction has been considered between the punch and the sheet, since lubrication has been applied during the blanking process.

\section{Results and discussion}

A first step has consisted in calibrating the shear failure model damage parameter for blanking simulation according to experimental observations. Then, blanking simulation has been performed with an initial worn punch geometry, and wear prediction has been carried out. 


\subsection{Damage parameter calibration}

\subsubsection{Calibration according to burnish height}

The shear failure model featured in Abaqus/Explicit® to include damage within blanking simulation has required the definition of equivalent plastic strain at failure $\overline{\mathcal{E}}_{f}^{p}$. The solution adopted in this study to identify $\bar{\varepsilon}_{f}^{p}$ value has been based on the comparison between experimental and numerical blanked sheet cut edge profiles. Makich [12] has measured burnish height and fracture height by means of confocal microscope (Alicona $\left.{ }^{\circledR}\right)$, and noticed that burnish zone and fracture zone evolved mainly during punch running-in wear stage (until 350,000 punch strokes), but tend to stabilize during punch steady-state wear stage (Fig.10).

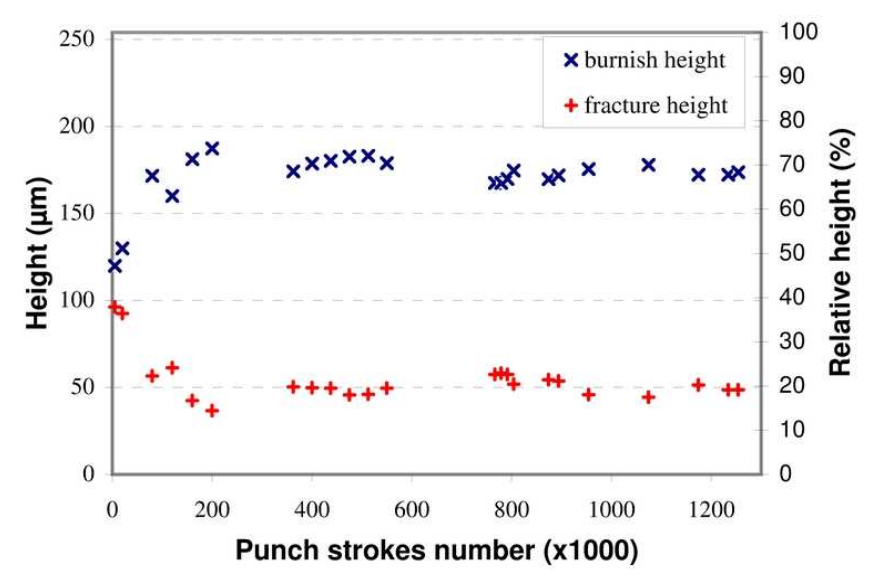

Fig. 10. Experimental measurements of cut edge profile for studied copper-alloy sheet.

In the present work, cut edge measurements have been provided for a worn profile after 1,174,000 punch strokes (Fig.11).

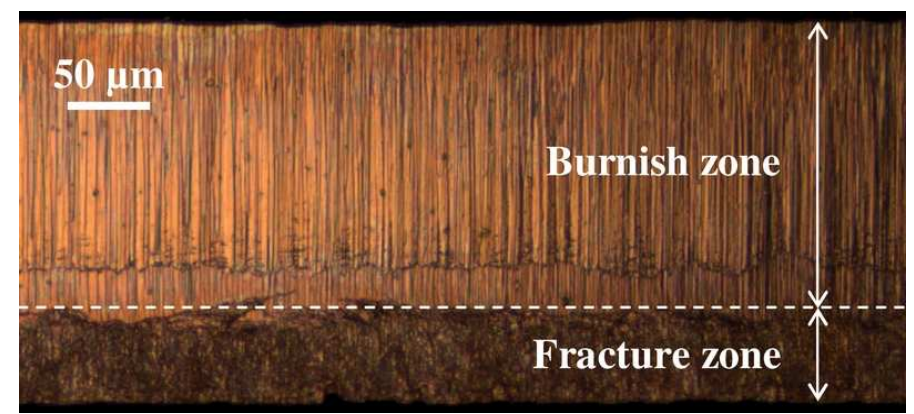

Fig. 11. Partial view of blanked sheet cut edge after 1,174,000 punch strokes. 
Due to progressive tool configuration, burr generated after one punch stroke is crushed against the die when the sheet is moved to perform consecutive press strokes. Thus, burr is not visible on blanked profile (Fig.11). A mean value of $172 \pm 4 \mu \mathrm{m}$ and $51 \pm 4 \mu \mathrm{m}$ has been obtained for burnish height and fracture height, respectively.

Once burnish height and fracture height have been acquired from the experimental profile of blanked edge (Fig.11), measurements of burnish height have been performed on numerical cut edge profiles. For this purpose, a parametric study with varying finite element size and shear failure damage parameter value has been conducted by finite element simulations. Four mesh sizes have been tested in the shearing zone to estimate the mesh influence on the cut edge profile. For each configuration, the following quantity of finite elements with respective element dimensions has been used: 1500 finite elements $(5.5 \times 9.1 \mu \mathrm{m}), 2500$ finite elements $(4.3 \times 7.1 \mu \mathrm{m}), 5000$ finite elements $(3.1 \times 5.1 \mu \mathrm{m})$, and 7500 finite elements $(2.8 \times 3.7 \mu \mathrm{m})$. Fig. 12 shows typical sheet cut edge profile obtained during this study for 5000 finite elements.

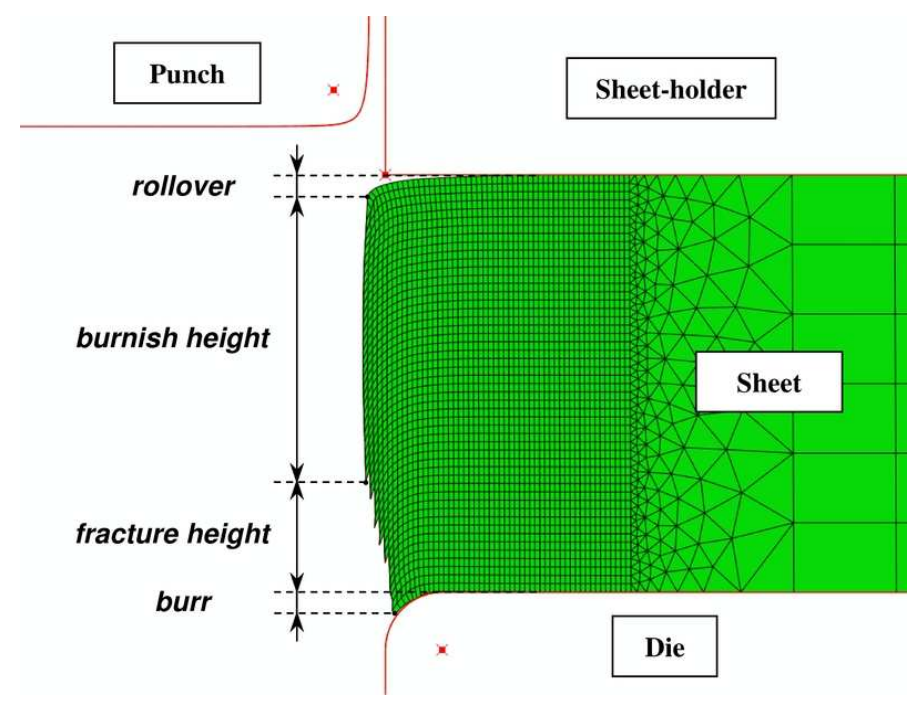

Fig. 12. Sheet cut edge profile after the punch travelled back to top stroke position (5000 finite elements). 
The different zones described in Fig.3 have been identified on numerical cut edge according to finite elements shape change, and burnish height and fracture height have been measured. The results of this parametric study are presented in Fig.13.

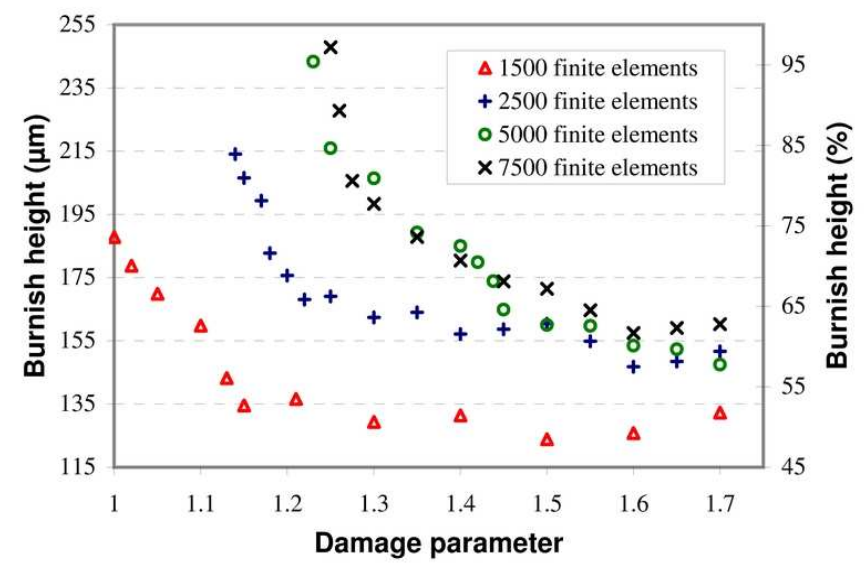

Fig. 13. Burnish height variation according to the damage parameter value $\bar{\varepsilon}_{f}^{p}$ and the mesh size.

For each mesh size, the minimum value of the damage parameter reported on Fig.13 corresponds to the limit under which fracture zone has no longer been identified on sheet cut edge since only burnish zone, burr and rollover have been formed. For the four tested mesh sizes, burnish height measurements show similar evolutions. Values reported are sensitive to damage parameter variation below a specific value $(1.15,1.22,1.45$, and 1.60 for 1500,2500 , 5000 and 7500 finite elements, respectively) and tend to stabilize beyond. Burnish height values show similar trends for meshes of 5000 and 7500 finite elements whatever the plastic strain at failure. This parametric study has illustrated sensitivity of burnish height measurements according to mesh size. However, similarities between results for 5000 and 7500 finite elements meshes suggest that less mesh sensitivity has been reached with a 5000 FE mesh, thus allowing to calibrate burnish height with experimental results. From this hypothesis, a value $\bar{\varepsilon}_{f}^{-p}=1.44$ has been estimated according to burnish height value of $172 \mu \mathrm{m}$ measured on 1,174,000 punch strokes cut edge profile. This damage parameter value has been used throughout the rest of this paper. 


\subsubsection{Stress triaxiality distribution}

The burnish height measurements on numerical cut edge profile have been performed by locating the transition point between rollover and burnish zone on the one hand, and between burnish zone and fracture zone on the other hand. The location of this second point has been emphasized according to a study on distribution of stress triaxiality ratio $\eta$ (which is defined as the ratio of the hydrostatic stress and the von Mises equivalent stress) along crack path. Measurements have been performed at integration point before element deletion occurred, with a 5000 FE mesh. Three main domains have been distinguished on Fig.14.
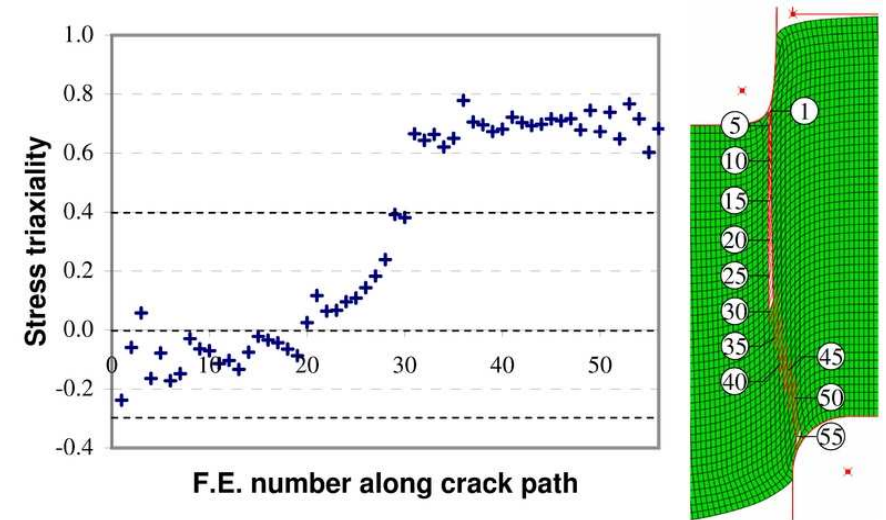

Fig. 14. Stress triaxiality of finite elements located in the crack path before element deletion and finite element numbering along blanked sheet crack.

The first one contains finite elements with negative stress triaxiality values. The second one presents stress triaxiality values regrouped between 0 and 0.4 . The third one consists in stress triaxiality values superior to 0.4 .

The present result can be discussed in the light of Bao and Wierzbicki [39] study. After performing various mechanical tests on ductile material for a wide range of stress triaxiality to characterize failure mode, Bao and Wierzbicki concluded that:

- for negative stress triaxialities $(-1 / 3<\eta<0)$, fracture is governed by shear mode.

- for intermediate values $(0<\eta<0.4)$ fracture occurs as a combination of shear and void growth modes. 
- for large triaxiality values $(\eta>0.4)$, void growth is the dominant failure mode.

According to these conclusions, the following observations have been made for the present work illustrated in Fig.14: finite elements located in the upper part of burnish zone (elements $\mathrm{n}^{\circ} 1$ to $\mathrm{n}^{\circ} 19$ ) have been subjected to shear failure mode, and lower part (elements $\mathrm{n}^{\circ} 20$ to $\mathrm{n}^{\circ} 30$ ) has been generated following a combination of shear and void growth failure modes. Fracture zone formed by finite elements $n^{\circ} 31$ to $n^{\circ} 56$ deletion has been mainly subjected to void growth failure mode. Distinguishing failure modes according to stress triaxiality values has put emphasis on finite elements $n^{\circ} 29$ and $n^{\circ} 30$, which appear close to the transition between the two failure regimes. This result correlates with burnish height measurement performed for damage parameter calibration, since these finite elements mark the transition between burnish zone and fracture zone.

The first finite element deleted during micro crack formation process was element $\mathrm{n}^{\circ} 2$, followed by $\mathrm{FE} \mathrm{n}^{\circ} 1$ as the punch's travel carried on. This result correlates with experimental observations made by Dalloz et al. [40] who noticed during shear cutting of $1.5 \mathrm{~mm}$ thick dual phase steel that micro crack initiation from void coalescence occurred few micrometers under the sheet surface.

\subsection{Blanking efforts}

Numerical simulation of the blanking process has allowed the computation of radial force besides the axial force which is commonly referred as blanking force. Fig.15a represents resultant efforts applied on punch as a function of punch cumulative displacement during downstroke travel and then upstroke travel. 

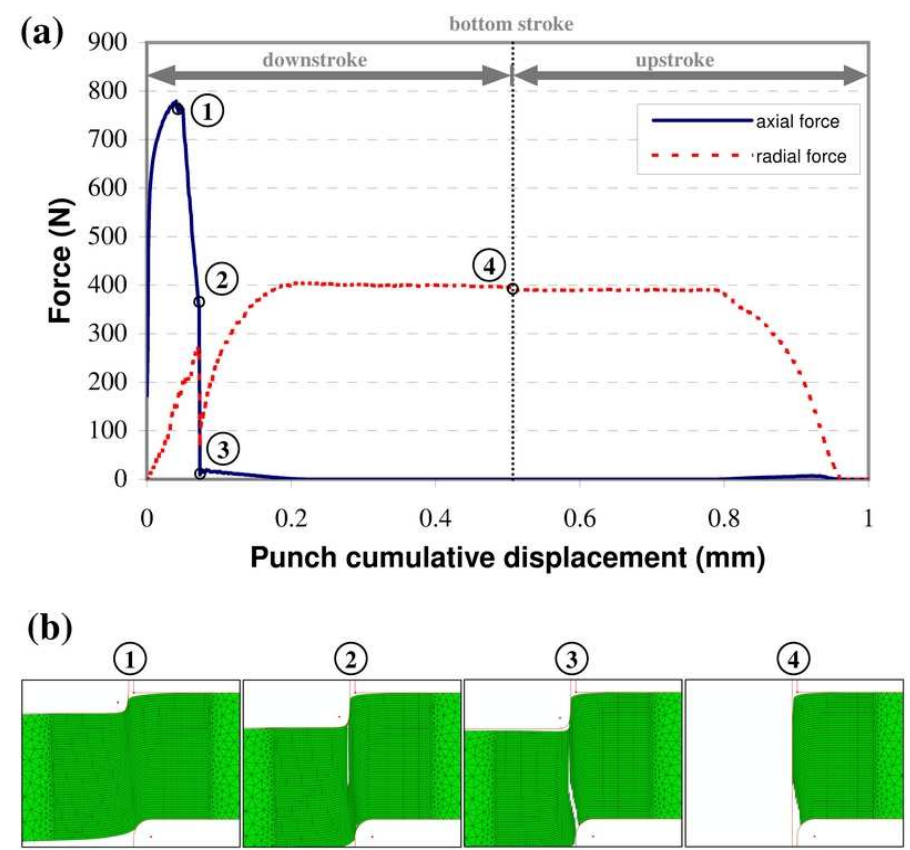

Fig. 15. (a) Axial and radial force versus punch cumulative displacement and (b) Sheet mesh at four damage states: 1 . first finite element deletion at $16 \%$ punch penetration; 2 . crack propagation and $\mathrm{FE}$ $\mathrm{n}^{\circ} 55$ deletion at $28 \%$ punch penetration; 3. complete separation of cut-end blanked part at $29 \%$ punch penetration; 4. punch at bottom stroke position.

Axial force evolves mainly during punch downstroke travel. Maximum blanking force equals $780 \mathrm{~N}$ and is reached just before first finite element deletion (Fig.15b-1) which happens at $16 \%$ punch penetration (relative to sheet thickness). Then, blanking force drops during the crack propagation, whereas finite element deletion happens near the die cutting edge (Fig.15b-2). Complete separation of blanked part occurs at $29 \%$ punch penetration (Fig.15b3). Regardless of the sheet thickness, this value correlates with Dalloz et al. [40] experimental work, with a $32 \%$ punch penetration at failure measured. From the moment complete crack occurs, resultant effort is mainly due to stress release in the vicinity of the punch flank, as illustrated by radial force curve. A slight drop of effort is recorded when punch reaches bottom stroke position (Fig.15b-4). Comparison between axial force work and radial force pseudo-work (area under each respective curve) generated during complete punch travel gives an energy ratio of nearly seven. 
Numerical wear results presented in the next section have been conducted with the damage parameter value estimated earlier and the 5000 finite elements mesh.

\subsection{Wear distribution and evolution}

Wear calculation has been performed by means of the wear algorithm based on equations presented in section 3.2. Wear coefficient value has been taken from experimental results (see section 2.3.1), and punch strokes number has been chosen to match with a known experimental worn profile configuration $\left(\mathrm{N}_{\mathrm{P}}=80,000\right)$. The wear distribution presented in Fig.16a has been obtained.

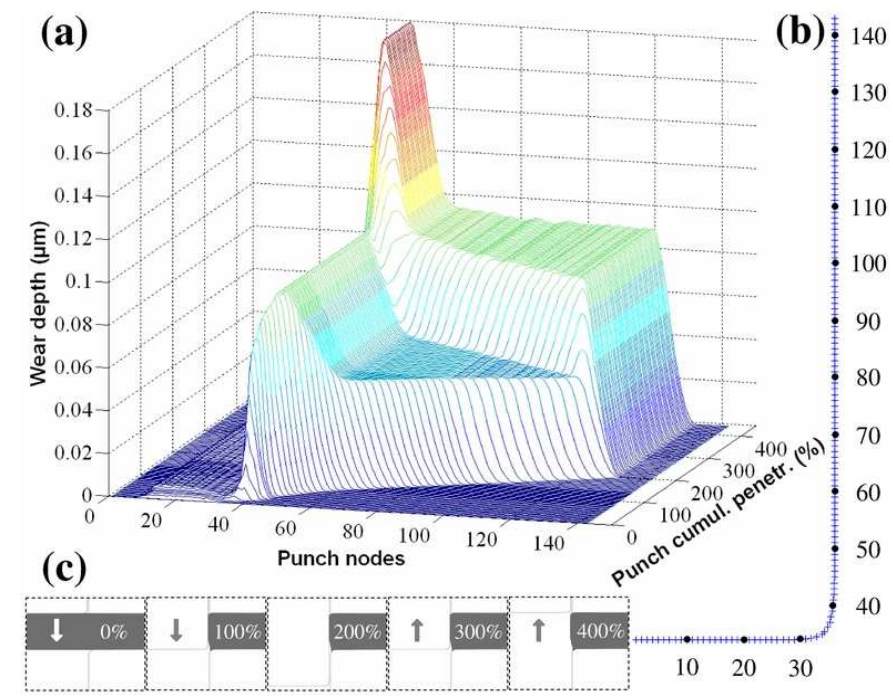

Fig. 16. (a) Wear evolution from worn profile at 1,174,000 strokes, (b) corresponding punch profile with node numbering, and (c) different punch cumulative penetrations relative to sheet thickness.

Punch penetration has been represented as a cumulative quantity relative to the sheet thickness for which a value of $200 \%$ corresponds to the bottom stroke position and $400 \%$ the final position after upstroke travel. Punch face wear located at punch nodes 1 to 30 shows minimum values as predicted by experimental results (Fig.6), and also observed on experimental worn profiles by Maeda and Aoki [41]. The "neutral" wear zone highlighted during previous study performed by Falconnet et al. [10] from a 766,500 punch strokes worn profile has still been noticed during wear calculation from a 1,174,000 strokes worn profile, 
near node 33. During downstroke travel (from 0 to $200 \%$ punch cumulative penetration), wear depth tends to evolve rapidly in punch cutting edge (nodes 37 to 40 approximately) to further develop on punch flank (nodes 41 to 121). It can be noticed that lower extremity of punch flank wear zone (from nodes 41 to 59) presents a significant increase of wear depth, with maximum value reached at node 45 . From $200 \%$ to $400 \%$ punch cumulative penetration (upstroke travel), punch flank wear is evenly developing as during downstroke travel but propagating from upper part to lower part of punch flank. Lower extremity of punch flank wear zone is even more developing as during downstroke travel, with maximum wear depth now localized at node 48 .

Wear generated during upstroke travel is mainly due to stress release that causes the sheet to "pinch" the punch. Moreover, extended contact duration between sheet and punch flank lower extremity during punch travel is the main cause of concentrated wear at this location. By comparing Fig.15a and Fig.16a, it is worth noting the similarity between axial force and punch face wear on the one hand, and between radial force and punch flank wear on the other hand.

Wear distributions presented in Fig.17 illustrate wear status at key instants of the simulation.

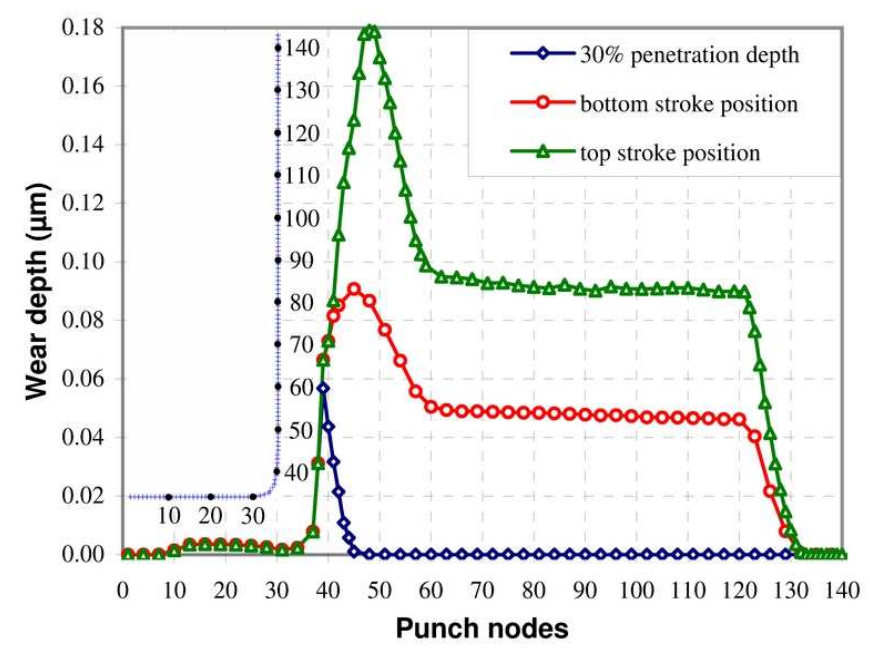

Fig. 17. Wear distribution at different punch penetrations. 
Wear distribution at $30 \%$ punch penetration represents punch wear status just after complete crack occurred. Compared to previous study of Falconnet et al. [10] where damage modelling was not taken into account, wear calculations performed in the present study have given further information about punch cutting edge wear and flank wear. As shown in Fig.17, wear distribution at bottom stroke position illustrates the contribution of sheet burnish edge contact on wear calculation during downstroke travel, and represents approximately $54 \%$ of the area delimited by wear distribution at top stroke position.

By comparing wear distributions from Fig. 17 with punch efforts represented in Fig.15a, links can be established between punch axial force and punch face wear on the one hand, and punch radial force and punch flank wear on the other hand. Rubenstein [42] has performed such a comparison by relating the amount of tool wear to the cutting force components in machining process. In Fig.17, punch face wear exhibits a minimum value because relative sliding between punch nodes and sheet surface nodes is almost nonexistent from sheet indentation phase until sheet separation at $29 \%$ punch penetration (contact loss). Moreover, contact pressures under the punch evolve around $0.7 \mathrm{GPa}$ but concern a reduced surface, which explains elevated value of blanking force reached by slightly affecting calculated wear depths. On the other hand, punch flank is subjected to a combination of important relative sliding and high contact pressures reaching average value of $1.3 \mathrm{GPa}$. This is due to stress release within the sheet that pinches the punch during downstroke and upstroke travel. Therefore, punch radial force remains preponderant for almost the whole blanking process duration, i.e. from the moment complete crack occurred to the end of punch upstroke travel. Axial and radial forces can be used as an indicator for qualitative wear prediction but they neglect the contribution of relative sliding between punch and sheet which is necessary for wear calculation according to Archard formulation. 


\subsection{Punch worn profile prediction}

In Fig.18, calculated wear depths have been reported on normal vectors at each punch node of the initial worn profile to build numerical worn profiles. The experimental fitting curve in Fig. 18 has been represented to show the initial state from which the numerical profile has been computed.

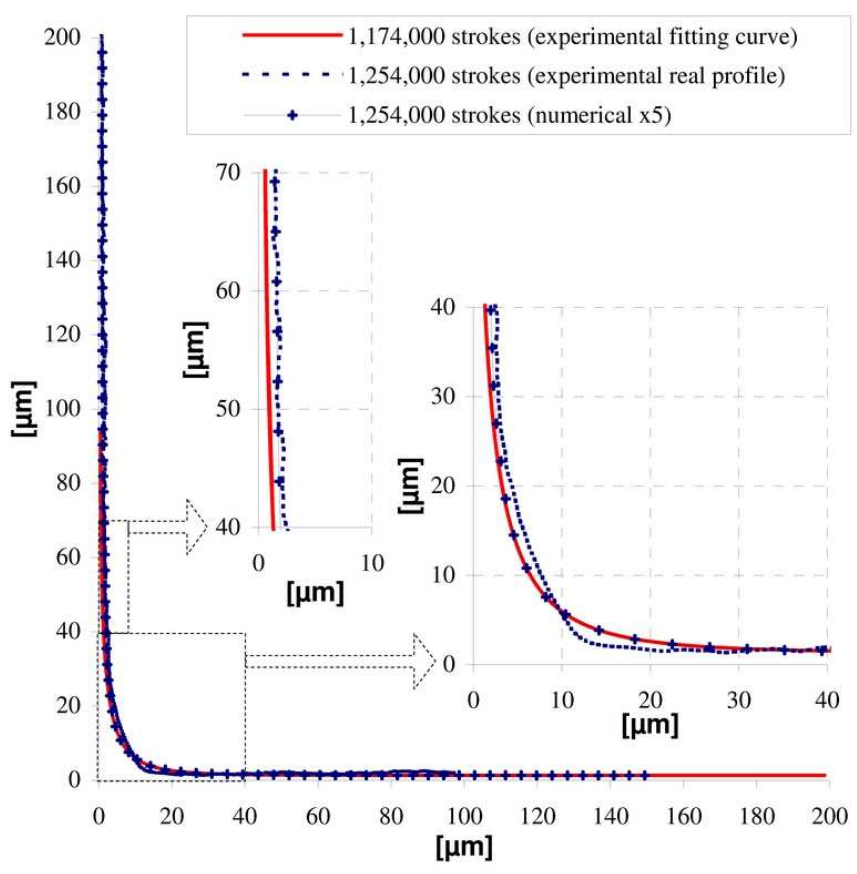

Fig. 18. Experimental worn profile at 1,174,000 and 1,254,000 punch strokes, and numerical worn profile.

In order to display the numerical profile despite low wear depths values in Fig.18, a magnification factor has been applied to computed wear depths. Concretely, the term" $K$ "in the second part of right hand side of Eq.(8) has been replaced with " $5 . K$ ". Most of calculated wear is located at punch flank, from ordinate 40 to $380 \mu \mathrm{m}$ approximately, and comes from the combination of important sliding distance and contact pressures. Wear depths computed at punch face nodes show almost no evolution since relative sliding between punch and sheet is nearly nonexistent under the punch. Due to sheet separation during crack propagation and to the gap created by the element deletion, a localized contact loss occurs and leads to no wear calculation between ordinate 5 and $18 \mu \mathrm{m}$. Observation of wear evolution on experimental 
worn profiles presented in Fig.6 shows important material loss for abscissa lower than $12 \mu \mathrm{m}$ in the punch cutting edge, which is not appearing on numerical worn profile. However, it appears that the "neutral" wear zone identified near abscissa $18 \mu \mathrm{m}$ of the numerical profile (Fig.18) matches a singular zone on experimental profile where no wear is observed until profile slope shift at abscissa $12 \mu \mathrm{m}$. It should be noticed from Fig. 6 that at this location, the punch fitting curve at $1,174,000$ punch strokes overestimates the real profile according to wear depth.

Wear calculation with Archard formulation seems appropriate to estimate punch flank wear since contact conditions in this zone are similar to a simple surface-to-surface tribological test. Thus, contact pressures and relative sliding computed from numerical simulation should tend to experimental values on punch flank. On the other hand, sheet motion and damage in cutting edge zone entails contact loss that impacts wear calculation, and therefore misrepresents punch cutting edge wear.

Wear coefficient measured by means of specific tribometer shows lower values compared to bibliography. For different material couples under unlubricated conditions, order of magnitude of wear coefficient $K$ varies over the range $10^{-2}-10^{-6} \mathrm{~mm}^{2} / \mathrm{N}$ according to Kalpakjian [43]. Finally, magnification of wear depths by a factor 5 allows the numerical profile and the real experimental profile to match in punch flank, as illustrated in Fig.18.

\subsection{Discussion}

In the context of blanking process simulation, damage and fracture models have to be taken into account for a more accurate description of the process, as they influence the stresses within the material and modify contact efforts on the tools. Ghosh et al. [34] have shown that the shear failure model predicts with quite accuracy the crack path and the cut edge profile for shearing process in comparison with experimental results. This practical model which 
requires only one damage parameter (the equivalent plastic strain at failure) to calibrate has been chosen in this study for its efficiency to simulate shear failure within blanking process. It should be noticed that the equivalent plastic strain at failure has been determined by comparing the measurement of the burnish height with FE numerical predictions for a specific set of blanking process parameters. If one of the process parameters such as sheet thickness, punch - die clearance, or tool radius is modified, it is necessary to recalibrate the corresponding value of the plastic strain at failure by using the same identification method. Much more sophisticated damage models such as modified GTN model for shear failure can be used to simulate blanking process, but they require several experimental tests to identify their numerous material parameters. In this study, the shear failure model has proven to be a suitable solution to investigate tool wear during blanking process in industrial context.

In this paper, some approximations have been made regarding friction conditions. The first one has consisted in using the tribometer presented in section 2.3.1 to approach contact condition observed during blanking, i.e. renewal of rubbing surface. However, during downstroke and upstroke travel of the punch, contact is mostly established between punch flank and sheet burnish zone (Fig.12) as illustrated by blanking simulation; contact between punch face and sheet virgin surface only happens during plastic indentation phase (until 16\% punch penetration, approximately). Wear coefficient obtained in this study by the tribometer characterizes wear between tungsten carbide pin and superficial layer of the sheet, instead of sheet inner material with pin, thus giving relatively low wear coefficient value. Another approach using pin-on-disc tribometer seemed more appropriate, but as demonstrated by Gréban [13], this configuration implies recycling of wear particles since wear track remains the same during experiment, which is not the case in blanking (wear particles are ejected). Linear tribometer with reciprocating motion seems to be an interesting alternative to match 
blanking friction conditions since wear particles are ejected and oxidation film is removed to reach sheet inner material. Such an experiment is under investigation.

The second approximation has concerned friction coefficient. In this study, no friction has been considered between punch and sheet. Since lubrication has been performed during blanking process, low friction coefficient values have been expected between tool and sheet. During preliminary settings of blanking simulations, introducing friction coefficient between tool and sheet has led to a reduction of the relative sliding and then a decrease in calculated wear depths according to Archard law. Thus, not considering friction during blanking simulations leads to an overestimation of computed wear depths. One way to consider friction coefficient in a wear model can be achieved according to an energy approach. This approach has been employed by several authors to link frictional work (i.e. energy dissipated by frictional forces) with wear volume. For example, Fouvry et al. [44] have introduced the energy wear coefficient (ratio of wear volume to frictional work) for quantitative comparison of different materials under fretting wear. Frictional energy is calculated from frictional force and sliding distance. Thus, this approach is equivalent to Archard law with a constant friction coefficient. The method proposed in this paper can be compared to an energy approach with a friction coefficient of one since Archard law uses normal load (i.e. from contact pressure) instead of frictional force.

Wear particles are supposed to be generated from the moment that relative motion exists between two contacting surfaces, i.e. the punch and the sheet. To translate this wear mechanism into finite element environment, wear calculation and punch geometry update should be performed at each time increment. Nevertheless, the computational cost to carry out such a modelling would be very expensive (as a matter of contact resolution, mesh and mechanical fields transfer, etc...). A strategy has been trialled to update the punch geometry at an intermediate step of the blanking simulation. Wear depths have been calculated and 
reported on initial punch profile $(1,174,000$ punch strokes) after it has reached bottom stroke position, and the blanking simulation has been pursued by replacing the punch profile with the corresponding updated punch geometry. In the paper of Hoffmann et al. [45], geometry update of deep drawing punch has been performed after each iteration, one iteration consisting in a forming simulation followed by a wear simulation. The trialled method with punch update offers similarities in the way that punch geometry update has been performed twice during an iteration (when the punch has reached bottom stroke, and when it has returned to top stroke position), but only one iteration has been achieved. However, this method has not been adopted for two main reasons. The first one is because almost no difference has been observed in wear distribution after punch update compared to the wear calculation performed without punch update. The second reason is related to the significant difference of punch strokes number to be simulated in blanking in comparison with deep drawing process.

\section{Conclusion}

In this work, sheet damage model has been introduced in thin sheet blanking simulation for complete modelling of the forming process. The method proposed to calibrate the damage parameter value has shown dependency toward finite element mesh size. However, less mesh sensitivity has been observed from the 5000 finite elements mesh, thus allowing calibration of the damage parameter according to burnish height. Moreover, the correlation between calibration method according to burnish height and results from the stress triaxiality study

performed along crack path has emphasized the choice on $\bar{\varepsilon}_{f}^{p}$ value by identifying the transition point between burnish zone generated by shear failure mode, and fracture zone obtained by combination of shear and void growth failure modes. Blanking simulations have been coupled to a wear algorithm established by means of experimental data gathered from 
Makich [12]. Compared to previous work [10], more information on punch wear has been accessed by introducing sheet failure modelling. Wear calculation performed along punch profile has revealed important wear starting from punch cutting edge to punch flank, whereas punch face remained almost unworn. A transition zone denoted "neutral" wear zone has still been identified in punch cutting edge lower part. The correlation between forces acting on punch and wear has offered possibilities for qualitative wear estimation but shows some limitations for providing quantitative results. Finally, wear profile computed by means of the wear algorithm has shown on the one hand similar trends on punch flank compared to experimental profile, but on the other hand a lack of accurate prediction in cutting edge zone. As perspective of this work, several fields of research could be investigated. The first one concerns optimization of mesh size in shear band to minimize crack width impact on wear calculation. The second one consists in increasing the frequency of punch profile updating to obtain a better description of punch wear evolution. Finally, further investigation should be performed on energy approach as an alternative wear model for prediction of abrasive tool wear in blanking process.

\section{Acknowledgements}

The authors would like to thank financial partners Région Franche-Comté, FEDER, Conseil Général du Doubs and Communauté d'Agglomération du Grand Besançon, which have made this research work possible.

\section{References}

[1] F. Gréban, G. Monteil, X. Roizard, Influence of the structure of blanked materials upon the blanking quality of copper alloys, J. Mater. Process. Technol. 186 (2007) 27-32. 
[2] T. Maeda, K. Matsuno, Wear on shearing tools, Japan Society of Mechanical Engineers 10 (1967) 197-205.

[3] C.F. Cheung, W.B. Lee, W.M. Chiu, An investigation of tool wear in the dam-bar cutting of integrated circuit packages, Wear 237 (2000) 274-282.

[4] G. Monteil, F. Gréban, X. Roizard, In situ punch wear measurement in a blanking tool by means of thin layer activation, Wear 265 (2008) 626-633.

[5] M.R. Jensen, F.F. Damborg, K.B. Nielsen, J. Danckert, Applying the finite element method for determination of tool wear in conventional deep-drawing, J. Mater. Process. Technol. 83 (1998) 98-105.

[6] B.-A. Behrens, F. Schaefer, Prediction of wear in hot forging tools by mean of finiteelement-analysis, J. Mater. Process. Technol. 167 (2005) 309-315.

[7] H. Torres, D. Horwatitsch, M. Varga, M. Schuster, K. Adam, M. Rodríguez Ripoll, Hot shearing processes : Correlation of numerical simulation with real wear phenomena, Tribol. Int. 82 (2015) 514-524.

[8] R. Hambli, BLANKSOFT : a code for sheet metal blanking processes optimization, J. Mater. Process. Tech. 141 (2003) 234-242.

[9] R. Hambli, Blanking tool wear modelling using finite element method, Int. J. Mach. Tools Manuf. 41 (2001) 1815-1829.

[10] E. Falconnet, H. Makich, J. Chambert, G. Monteil, P. Picart, Numerical and experimental analyses of punch wear in the blanking of copper alloy thin sheet, Wear 296 (2012) 598-606.

[11] W. Johnson, R. Slater, A survey of the slow and fast blanking of metals at ambient and high temperatures, Proc. Int. Conf. Manuf. Techn., Michigan, 1967 pp. 773-851. 
[12] H. Makich, Etude théorique et expérimentale de l'usure des outils de découpe; Influence sur la qualité des pièces découpées, Ph.D. Thesis, University of Franche-Comté, Besançon, France, 2011.

[13] F. Gréban, Découpabilité du cuivre et des alliages cuivreux, Ph.D. Thesis, University of Franche-Comté, Besançon, France, 2006.

[14] J.F. Archard, Contact and rubbing of flat surfaces, J. Appl. Phys. 24 (1953) 981-988.

[15] J.J. Hernandez, P. Franco, M. Estrems, F. Faura, Modelling and experimental analysis of the effects of tool wear on form errors in stainless steel blanking, J. Mater. Process. Technol. 180 (2006) 143-150.

[16] R. Shivpuri, S. Singh, K. Agarwal, C. Liu, Energy release rate based approach for the wear of punches in precision blanking of high strength steel, CIRP Ann-Manuf. Techn. 60 (2011) 307-310.

[17] A.G. Atkins, Surfaces produced by guillotining, Phil. Mag. A 43 (1981) 627-641.

[18] V. Lemiale, J. Chambert, P. Picart, Description of numerical techniques with the aim of predicting the sheet metal blanking process by FEM simulation, J. Mater. Process. Technol. 209 (2009) 2723-2734.

[19] E. Taupin, J. Breitling, W.T. Wu, T. Altan, Material fracture and burr formation in blanking results of FEM simulations and comparison with experiments, J. Mater. Process. Technol. 59 (1996) 68-78.

[20] F.A. McClintock, A criterion for ductile fracture by the growth of holes, J. Appl. Mech. 35 (1968) 363-371.

[21] A.M. Goijaerts, L.E. Govaert, F.P.T. Baaijens, Evaluation of ductile fracture models for different metals in blanking, J. Mater. Process. Technol. 110 (2001) 312-323. 
[22] J.R. Rice, D.M. Tracey, On the ductile enlargement of voids in triaxial stress fields, J. Mech. Phys. Solids. 17 (1969) 201-217.

[23] M. Farzin, H.R. Javani, M. Mashayekhi, R. Hambli, Analysis of blanking process using various damage criteria, J. Mater. Process. Technol. 177 (2006) 287-290.

[24] ABAQUS/Explicit - HKS, 2011. Abaqus Analysis User's Manual - Version 6.11.

[25] R. Hambli, A. Potiron, Finite element modeling of sheet-metal blanking operations with experimental verification, J. Mater. Process. Technol. 102 (2000) 257-265.

[26] J. Lemaitre, A continuous damage mechanics model for ductile fracture, J. Eng. Mater. Technol. 107 (1985) 83-89.

[27] W. Klingenberg, U.P. Singh, Finite element simulation of the punching/blanking process using in-process characterisation of mild steel, J. Mater. Process. Technol. 134 (2003) 296302.

[28] A.L. Gurson, Continuum theory of ductile rupture by void nucleation and growth: Part I-Yield criteria and flow rules for porous ductile media, J. Eng. Mater. Technol. 99 (1977) $2-15$.

[29] V. Tvergaard, A. Needleman, Analysis of the cup-cone fracture in a round tensile bar, Acta Metall. 32 (1984) 157-169.

[30] K. Nahshon, J.W. Hutchinson, Modification of the Gurson model for shear failure, Eur. J. Mech. A Solids 27 (2008) 1-17.

[31] K.L. Nielsen, V. Tvergaard, Ductile shear failure or plug failure of spot welds modelled by modified Gurson model, Eng. Fract. Mech. 77 (2010) 1031-1047. 
[32] M. Achouri, G. Germain, P. Dal Santo, D. Saidane, Experimental and numerical analysis of micromechanical damage in the punching for high-strength low-alloy steels, Mater. Design. 56 (2014) 657-670.

[33] M. Achouri, G. Germain, P. Dal Santo, D. Saidane, Experimental characterization and numerical modeling of micromechanical damage under different stress states, Mater. Des. 50 (2013) 207-222.

[34] S. Ghosh, M. Li, A. Khadke, 3D modeling of shear-slitting process for aluminium alloys, J. Mater. Process. Technol. 167 (2005) 91-102.

[35] D. Lepadatu, R. Hambli, A. Kobi, A. Barreau, Statistical investigation of die wear in metal extrusion processes, Int. J. Adv. Manuf. Technol. 28 (2006) 272-278.

[36] K. Ersoy-Nürnberg, G. Nürnberg, M. Golle, H. Hoffmann, Simulation of wear on sheet metal forming tools - An energy approach, Wear 265 (2008) 1801-1807.

[37] G. Pijaudier-Cabot, Z.P. Bazant, Nonlocal damage theory, J. Eng. Mech.-ASCE. 113 (1987) 1512-1533.

[38] R. Hambli, Etude expérimentale, numérique et théorique du découpage des tôles en vue de l'optimisation du procédé, Ph.D. Thesis, ENSAM, Angers, France, 1996.

[39] Y. Bao, T. Wierzbicki, On fracture locus in the equivalent strain and stress triaxiality space, Int. J. Mech. Sci. 46 (2004) 81-98.

[40] A. Dalloz, J. Besson, A.-F. Gourgues-Lorenzon, T. Sturel, A. Pineau, Effect of shear cutting on ductility of a dual phase steel, Eng. Fract. Mech. 76 (2009) 1411-1424.

[41] T. Maeda, I. Aoki, The study on wear of blanking tool for 18-8 stainless steel and bainite hardened steel strips, J. of the Faculty of Engineering, University of Tokyo Series B XXXII (1974) 443-475. 
[42] C. Rubenstein, An analysis of tool life based on flank-face wear, J. Eng. Ind. 98 (1976) 221-226.

[43] S. Kalpakjian, Manufacturing processes for engineering materials, fourth ed., Prentice Hall, New Jersey (2002) pp. 141.

[44] S. Fouvry, P. Kapsa, L. Vincent, Quantification of fretting damage, Wear 200 (1996) $186-205$

[45] H. Hoffmann, C. Hwang, K. Ersoy, Advanced wear simulation in sheet metal forming, CIRP Ann. - Manuf. Technol. 54 (2005) 217-220. 